УДК 902

https://doi.org/10.24852/2587-6112.2020.5.25.28

\title{
ТЕХНОЛОГИЯ ПОДГОТОВКИ КОСТНОГО МАТЕРИАЛА ДЛЯ ЕГО ПОСЛЕДУЮЩЕЙ ОБРАБОТКИ И ИЗГОТОВЛЕНИЯ ИЗДЕЛИЙ: ЭКСПЕРИМЕНТАЛЬНЫЕ ДАННЫЕ
}

\author{
(C) 2020 г. М.Е. Шмырина
}

В работе представлены основные результаты произведенного эксперимента, связанного с восстановлением технологии обработки кости. Целью исследования автора являлось выделение основных этапов в обработки кости, а также фиксация ключевых моментов, связанных со временем обработки материала. Основой данной работы стал эксперимент, исходя из которого, делаются выводы о косторезном производстве, получившем широкое распространение на территории Пермского Предуралья. Автором рассмотрен инструментарий, который использовался для проведения работ с костяным сырьем.

Ключевые слова: археология, кость, костяные изделия, технология, вываривание.

\section{TECHNOLOGY OF BONE MATERIAL PREPARATION FOR ITS PROCESSING AND MANUFACTURE OF PRODUCTS: EXPERIMENTAL INFORMATION}

\begin{abstract}
M.E. Shmirina
The paper presents the main results of an experiment related to the restoration of the bone processing technology. The author's research purpose was to highlight the main stages in bone processing, as well as to ascertain the important points related to the processing time of the material. In the basis of research there was the experiment, based on which the conclusions are made about bone-cutting production, which has become widespread in the territory of the Perm Cis-Urals. The author considers the tools which were used for working with bone raw materials.
\end{abstract}

Keywords: archaeology, bone, bone products, technology, extraction.

Кость и рог являются одними из самых распространенных материалов, который средневековый человек использовал в своей обыденной жизни. Территория Пермского Предуралья не стала исключением. Распространенность костяных изделий можно обосновать легкостью обработки данного материала, а также его распространенностью. Более распространенным и простым в обработке материалом можно считать дерево. В то же время деревянные предметы менее прочные в отличие от костяных и более подвержены внешним воздействиям. Кость можно использовать почти во всех областях жизни человека. В средневековье кость становится одним из наиболее распространенных материалов на территории Пермского Предуралья (Ленц, 2002).

В Средневековье кость применялась для изготовления множества категорий вещей. Одними из самых распространенных предметов являются орудия труда для домашних производств. Данная категория включает различные орудия для прядения и ткачества, обработки кожи, а также рукояти ножей и шильев. Менее многочисленной категорией вещей можно считать предметы вооружения и охоты. В данную группу предметов можно включить наконечники стрел, манки, детали конской и собачей упряжи, различные накладки, необходимые для стрельбы из лука. На большинстве памятников встречаются также предметы туалета и детали костюма. В эту категорию вещей включаются роговые и костяные гребни, расчески, пуговицы, копоушки и амулеты. Для материала многих памятников Пермского Предуралья характерно наличие предметов для игр и музыкальных инструментов. Предметы для игр зачастую представлены бабками или альчиками, изготовленными из астрагалов домашнего скота (Белавин, Крыласова, 2008). Среди музыкальных инструментов на территории Пермского Предуралья были встречены костяная флейта (Сарапулов, 2017) и костяные варганы.

Для изготовления костяных предметов в большинстве случаев использовались кости животных, которых употребляли в пищу. В частности, обрабатывались кости крупного и мелкого рогатого скота, рыб, куниц, бобра, собаки, а также лося и оленя. Для изготовления костяных предметов возможно использо- 
вание большинства костей скелета животного, но предпочтение в выборе материала отдавалось трубчатым костям и передним лапам животных, которые обладают большей прочностью (Изюмова, 1949).

Являясь достаточно распространенным материалом, кость использовалась повсеместно, начиная с палеолита, заканчивая недавним прошлым. Рядом археологов были произведены эксперименты, связанные с реконструкцией процесса изготовления костяных предметов. Часть исследователей концентрировала свое внимание на технологиях, применение которых имело место для каменного века, другая же часть сосредоточила свои исследования на Средневековье. Наличие размягчителя, воздействию которого подвергалась кость, не вызывает споров среди исследователей. Так, например, Ю.Б. Сериков выделил технологию, согласно которой размягчение и обезжиривание кости и рога возможно достичь с помощью вымачивания материала в смеси золы с водой в течение длительного промежутка времени, либо же с помощью вываривания со щавелевой кислотой (Сериков, 2018). Г.Т. Ленц в своих исследованиях также выделяет ряд составов, которые могут способствовать обезжириванию и размягчению кости, например, кисломолочные продукты, щелок или мочевина (Ленц, 2002). Стоит отметить, что ряд исследователей основывает свои выводы на этнографических данных, другие же ориентируются на современные технологии обработки костного материала.

В целом стоит отметить, что для косторезного производства выделяется особый набор инструментов. Данные орудия обработки кости могут быть как универсальными для всех областей производства средневекового человека, так и быть специализированными. Наиболее распространенными и универсальными орудиями для обработки кости и рога можно считать нож и топор, которые необходимы как для первоначальной обработки сырья, так и для дальнейшей работы с ним. Для более сложных работ могли применяться пилы, сверла, долота, напильники, резцы. Для орнаментации могли использоваться различные циркули. Также для первоначальной обработки кости могли использоваться рога и его отростки, а также различные пробойники, необходимые для удаления внутренних тканей кости и рога. Стоит также отметить, что для Пермского Предуралья характерны следы применения простейшего токарного станка, хотя его детали на данный момент не были встречены (Ленц, 2002). Специфическими же инструментами для обработки кости можно считать определенного вида ножи. Исследователи считают, что ножи, имеющие прямое лезвие и «горбатую» спинку с плавным уступом, являются специализированными орудиями для обработки кости (Белавин, Крыласова, 2008). Среди материалов памятников Пермского Предуралья встречаются также пилы небольших размеров, которые можно интерпретировать как пилочки для пропиливания зубцов гребней.

Для нашего эксперимента по воссозданию технологии обработки костяных изделий были выбраны кости коровы: ребра и трубчатые кости передней ноги. Для размягчения и обезжиривания костей при вываривании использовался щелок и кисломолочные продукты (молочная сыворотка). В качестве инструментов для обработки кости выступили топор (для разрубки костей) и пила (с помощью которой были отпилены суставы и части скелета, которые не представляли интереса при проведении эксперимента). Также для придания кости необходимой формы использовались кухонные ножи с плоскими лезвиями.

Первичным этапом в обработке кости стало удаление излишков, костного мозга, а также разделение костей. Изначально у трубчатой кости были удалены примыкающие к ней суставы. Данная операция была произведена при помощи подпиливания по окружности кости. Затем излишки были отколоты при помощи молотка. Ребро было поделено на две части. От костей также были отделены оставшиеся части мышечной ткани. На данном этапе первичная подготовка сырья была завершена.

Bторым этапом в обработке кости стало ее обезжиривание и размягчение. Данная часть эксперимента происходила в двух вариантах. Первая часть костей была выварена со щелоком (золой), для обезжиривания второй части костей использовалась молочная сыворотка. В первом случае в железную кастрюлю были помещены все кости, засыпано 5 столовых ложек золы, а также 3 литра воды. Наименьшая из костей ребра (25 см) вываривалась на протяжении 4-х часов. Оставшиеся кости вываривались на протяжении 7-ми часов. Во втором случае происходило вываривание двух костей в 2-х литрах молоч- 
ной сыворотки. По мере вскипания и испарения жидкости в сыворотку добавлялась вода. В данном случае вываривание происходило на протяжении 5-ти часов.

Третьим этапом стала обработка костяного сырья при помощи ножей и пилы. От костей были удалены излишки, которые не представляли интереса при обработке. Стоит отметить, что после продолжительного вываривания костей не удалось добиться достаточной пластичности и мягкости, которая бы позволила с легкостью выполнить различные операции по изменению формы и выполнению фигурной резки кости. Костяной материал, который длительное время вываривался совместно со щелоком (золой), приобрел характерный серый цвет и пористую структуру, в то время как кости, которые подвергались обработке в молочной сыворотке, приобрели желтый оттенок и остались достаточно гладкими. Возможно, недостаточная пластичность костного материала связана с малым временем его вываривания. Кости, которые были выварены в обоих растворах, наиболее хорошо поддаются строганию, хоть и со значительными усилиями. Наиболее податливым материалом в обработке стало ребро коровы, из которого с помощью пилы и плоского ножа был сделан кочедык.

Четвертым этапом в обработке кости стала шлифовка изделия с помощью песка и нанесение орнамента. После вываривания и придания необходимой формы кость, вываренная в золе, оставалась пористой и шершавой. С помощью песка с примесью мелкой гальки и воды была произведена шлифовка (натирание) изделия, благодаря чему оно стало более гладкое. Далее был нанесен прорезной геометрический линейный орнамент или так называемая «косая решетка». Для орнаментации изделия использовался кухонный нож с лезвием без зубцов. Данный орнамент можно считать наиболее распространенным для костяных изделий (Маврина, 2015). На данном этапе обработку костного материала и изготовление костяного предмета можно считать завершенным.

Стоит отметить, что костяное изделие, полученное в ходе эксперимента, отличается структурой материала и цветом от тех предметов, которые встречаются в материалах археологических памятников. Вероятнее всего, в Средневековье костяные изделия первоначально выглядели схожим образом, но по мере их применения в обиходе человека кость становилась более заполированной, гладкой и привычной для глаза. Также для проведения будущих экспериментов, связанных с косторезным производством, необходимо учитывать время вываривания, которое, на наш взгляд, в данном случае было недостаточным.

Подводя итог, можно говорить о том, что вываривание со щелоком (золой) было более эффективным. Материал, полученный с помощью данного раствора, показал себя более пластичным и податливым в обработке, чем материал, который был обезжирен и размягчен с помощью кисломолочных продуктов. Также стоит отметить универсальность орудий, которые могли использоваться для обработки кости. Для достижения большей точности и установления подхода к косторезному производству средневекового человека требуются дальнейшие исследования.

\section{ЛИТЕРАТУРА}

Белавин А.М., Крыласова Н.Б. Древняя Афкула: археологический комплекс у с. Рождественск. Пермь: Перм. гос. пед. ун-т., 2008. 603 с.

Изюмова С.А. Техника обработки кости в дьяконовское время и в Древней Руси // КСИИМК. Вып. XXX. М: Академия наук СССР, 1949. С. 15-25.

Лени Г.Т. Косторезное производство в Верхнем Прикамье // Очерки археологии Пермского Предуралья: Учебное пособие для студентов и аспирантов. / Под ред. А.М. Белавина. Пермь: ПГПУ, 2002. C. $217-242$.

Маврина Е.А. Особенности орнаментации костяных изделий средневековых памятников Пермского Предуралья // Труды КАЭЭ ПГГПУ. Вып. 10. / Отв. ред. Н.Б. Крыласова. Пермь: ПГГПУ, 2015. C. $152-162$.

Сарапулов А.Н. Отчет о раскопках Полютово (Роданово) городища в Юсьвинском районе Пермского края в 2017 году / Архив МАЭ ПГГПУ, 2017.

Сериков Ю.Б. Реконструкция технических приемов обработки камня и кости в каменном веке // Геоархеология и археологическая минералогия - 2018. Научное издание. Материалы V Всероссийской молодежной научной школы Миас: Институт минералогии УрО РАН, 2018. №5. С. 66-71. 


\section{Информация об авторе:}

Шмырина Мария Евгеньевна, Пермский государственный гуманитарно-педагогический университет (г. Пермь, Россия); mashah98@mail.ru

\section{REFERENCES}

Belavin, A. M., Krylasova, N. B. 2008. Drevniaia Afkula: arkheologicheskii kompleks u s. Rozhdestvensk (Ancient Afkula: the Archaeological Complex near the Rozhdestvensk Village). Perm: Perm State Pedagogical University (in Russian).

Iziumova, S. A. 1949. In Kratkie soobshcheniia Instituta istorii material'noi kul 'tury (Brief Communications of the Institute for the History of Material Culture) XXX. Moscow: Academy of Sciences of the USSR, 15-25 (in Russian).

Lents, G. T. 2002. In Belavin, A. M. (ed.). Ocherki arkheologii Permskogo Predural'ia. Uchebnoe posobie dlia studentov $i$ aspirantov (Essays on the History of Perm Cis-Urals: Textbook for graduate and post-graduate students). Perm: Perm State Pedagogical University, 217-242 (in Russian).

Mavrina, E. A. 2015. In Krylasova, N. B. (ed.). Trudy Kamskoi arkheologo-etnograficheskoi ekspeditsii (Proceedings of the Kama Archaeological and Ethnographical Expedition) VI. Perm: Perm State Humanitarian Pedagogical University, 152-162 (in Russian).

Sarapulov, A. N. 2017. Otchet o raskopkakh Polyutovo (Rodanovo) gorodishcha v Yus'vinskom rajone Permskogo kraia v 2017 godu (Report on the Excavations at Polyutovo (Rodanovo) Settlement in the Yusvinsky District of the Perm Region in 2017). Perm. Archive of the Perm State Humanitarian Pedagogical University (in Russian).

Serikov, Yu. B. 2018. Geoarkheologiia i arkheologicheskaia mineralogiia-2018. Nauchnoe izdanie. Materialy IV Vserossiiskoi molodezhnoi nauchnoi shkoly (Geoarchaeology and Archaeological mineralogy - 2018. Scientific Publication. Proceedings of the 5th All-Russian Youth Scientific School). Miass: Institute of Mineralogy. Ural Branch of the Russian Academy of Sciences, 66-71 (in Russian).

\section{About the Author:}

Shmirina Maria E. Perm State Humanitarian Pedagogical University (PSHPU). Sibirskaya Str., 24, Perm, 614990, Russian Federation; mashah98@mail.ru 